\title{
Trabalho na agroindústria açucareira de Alagoas
}

\author{
Alice Anabuki Plancherel ${ }^{1}$ \\ Cícero Ferreira de Albuquerque ${ }^{2}$ \\ Sérgio Ricardo Gomes dos Santos Melo ${ }^{3}$
}

Resumo: O presente texto apresenta, numa perspectiva histórico-estrutural, a preocupação quanto às condições subumanas de vida e de trabalho que o capital agroindustrial açucareiro impõe aos trabalhadores do corte de cana no estado de Alagoas. Esta última delimitação territorial visa atender ao objeto de investigação de uma pesquisa histórico-concreta, realizada no âmbito do Grupo de pesquisa/CNPq Trabalho e capitalismo contemporâneo, em torno da relação capital e trabalho na atividade açucareira contemporânea; tem ainda por suposto que nela se expressa, regionalmente, um processo de socialização do trabalho que se aprofunda num movimento de sua (des)estruturação sob a desregulação do mercado de trabalho em vigor no país, a partir dos anos 1990, em concomitância à própria desregulamentação estatal do capital agroindustrial canavieiro, enquanto parcela das "soluções" neoliberais ao aprofundamento de uma crise econômica mais geral. Ao fim da pesquisa, o estudo tem em vista contribuir para a história dos canavieiros no país, destacando algumas especificidades regionais de suas organizações e de suas lutas.

Palavras-chave: atividade agroindustrial açucareira, socialização do trabalho, canavieiros assalariados, Estado de Alagoas.

\footnotetext{
${ }^{1}$ Membro do Programa de Pós-Graduação em Sociologia da Universidade Federal de Alagoas e líder do Grupo de Pesquisa/CNPq Trabalho e capitalismo contemporâneo; E-Mail: plancherel@uol.com.br.

${ }^{2}$ Mestre em Sociologia pela Universidade Federal de Pernambuco e co-líder do Grupo de Pesquisa/CNPq Trabalho e capitalismo contemporâneo; E-Mail: cicerofalbuquerque@hotmail.com.

${ }^{3}$ Mestrando do Programa de Pós-Graduação em Sociologia da Universidade Federal de Alagoas; E-Mail: sergio_gomes08@hotmail.com.

Registramos ainda agradecimentos especiais a todos demais membros do supracitado Grupo de Pesquisa, com os(as) quais os seus líderes tiveram o privilégio de discutir uma primeira versão deste artigo, posteriormente em grande medida reformulado. A autora e os autores, em particular, se submetem à responsabilidade pela versão final.
}

Latitude, Vol. 1, n'2, pp.119-134, 2007. 


\title{
Work in the sugar agro-industry of Alagoas
}

\begin{abstract}
This text presents, in a structural historic perspective, the concern of the subhuman conditions of life and work that the sugar agro-industrial capital imposes on the people who work in the sugar cane fields in the state of Alagoas. This last territorial delimitation aims to answer the investigational purpose of a historicconcrete research, conducted within the scope of the Grupo de Pesquisa/ CNPq Trabalho e Capitalismo contemporâneo (Research Group/ CNPq Labour and Capitalism contemporary), around the capital-labour relation in contemporary sugar cane activity; where it is supposed to express, regionally, a process of socialization of labour which deepens in the movement of its (de-)structuring under the labour market deregulation in place at Brazil, from 1990, concomitantly with the own state deregulation of sugar cane agro-industrial capital, while aspect of the neoliberal "solutions" to the deepening of an economic depression more general. Finally, the study intends to contribute to the history of sugar cane workers in the country, pointing out some regional specificities of their organizations and their struggles.
\end{abstract}

Key-words: sugar agro-industrial activity, socialization of labour, sugar cane employees, state of Alagoas.

\section{Introdução}

De esteio da economia regional, a atividade açucareira do Nordeste brasileiro torna-se considerada, no presente, já antiga e decadente (OLIVEIRA, 2007, p. 7); no estado de Alagoas, no entanto, ela ainda representa a principal base econômico-social na qual se assentam o predomínio político do capital agroindustrial e formas de socialização e de (des) estruturação do trabalho que as contemporizam inclusive do ponto de vista sociológico. Daí, também nesta última base territorial, a história do trabalho agroindustrial canavieiro não se inscrever menos "na galeria de Marx, Dickens e Zola na descrição dos horrores de uma forma de exploração tão brutal que mal acreditamos se passar em pleno século XXI" (id, ibid., p. 7), a ponto de impulsionar um dos objetivos do Grupo de pesquisa/CNPq Trabalho e capitalismo contemporâneo: apreender as efetivas condições de vida e de trabalho de uma categoria social constituída, na contemporaneidade, de canavieiros assalariados contratualmente permanentes, canavieiros assalariados "sazonalmente" temporários e de pequenos produtores "temporariamente" canavieiros assalariados e migrantes do próprio sertão alagoano; os dois últimos, sobretudo, submetidos de maneira

Latitude, Vol. 1, n², pp.119-134, 2007. 
diferenciada e mais agudamente ao crescente processo de "precarização do precário" e do desemprego estrutural.

Tomar ainda as relações de trabalho na produção agroindustrial açucareira como objeto de pesquisa significa remeter a um universo no qual o capital nunca teve limites de exploração nem dos recursos naturais nem das condições humanas de vida; significa, enfim, investigar uma realidade histórico-concreta na qual a degradação do meio ambiente e do mundo do trabalho, sob a voracidade destrutiva do capital agroindustrial, alcança níveis extremos de exploração: a precarização exponencial de uma atividade laboral, já antes extraordinariamente precária, desde a sua parte agrícola; uma realidade de incessante "precarização do precário" do trabalho assalariado livre e temporário - do canavieiro, em especial, sobre o qual nos debruçaremos.

Em Alagoas, os impactos da reestruturação produtiva e do conjunto de mudanças implementadas no processo de produção do açúcar alteram e agravam profundamente as condições objetivas de vida do canavieiro, em particular, e se desdobram, inclusive, numa mudança da própria subjetividade do trabalho tanto quanto do capital em face daquelas alterações ${ }^{4}$. À primeira vista, aliás, observa-se visivelmente que a cana-de-açúcar é uma cultura de forte presença e impacta todo o universo de uma região na qual se instala como atividade econômica; em torno dela e da produção do açúcar, surge uma "civilização" particular: o espaço geográfico passa a apresentar-se horizontalmente sob uma devastadora monopolização da terra e, no seu reverso, sob uma desigualdade social cuja modernização assume claras especificidades e assimetrias em suas relações sociais e em suas conformações políticas. A monocultura do açúcar e o seu corolário, o latifúndio, tornam-se tão avassaladores que, não raras vezes, chegam a inviabilizar o surgimento e a efetivação de outras atividades econômicas na mesma região. Não sem razão, alguns autores definem a cultura da cana-de-açúcar como sendo tradicionalmente monopolista (WANDERLEY, 1979; ANDRADE, 1998).

À precarização de um trabalho já antes precário sob a secular produção açucareira em Alagoas, seu aprofundamento reforça-se sob a crise brasileira nas últimas duas décadas (1980-2000) e sob as "soluções" adotadas, uma vez mais, pelo governo central desde os anos 1980: a política neoliberal de desregulamentação da economia, em especial, rebate na própria desregulamentação do capital agroindustrial açucareiro e, via institucionalização da flexibilidade dos contratos de trabalho, não menos na desregulação da força de trabalho na qual se assenta a acumulação e a reprodução ampliada do capital agroindustrial. Decorrente das propostas do Consenso de Washington, sob quais efeitos de tais medidas se reforça a "precarização do

4 A respeito da reestruturação produtiva na agroindústria sucroalcooleira alagoana ver Carvalho, Cícero Péricles de Oliveira (2000).

Latitude, Vol. 1, n², pp.119-134, 2007. 
precário" que grassa entre os assalariados canavieiros temporários, aliás, não apenas alagoanos?

Reconhecidamente tem-se-lhes atribuído uma especificidade laboral, cuja intermitência compatibilizar-se-ia com a própria sazonalidade natural dos produtos agrícolas de maneira geral. Persistiria, contudo, relevante a primazia desta especificidade na caracterização do trabalho assalariado "sazonalmente" temporário e do pequeno produtor agrícola "temporariamente" canavieiro sertanejo? Resistiriam, assim, ambos à sua diversificação sob formas complexas e heterogêneas de desemprego (friccional, cíclico, sazonal, estrutural, oculto etc.)? Ou formariam um excedente de força de trabalho, um exército agrícola de reserva, em Marx, mutatis mutandis, conceituado como o exército industrial de reserva ${ }^{5}$ Como esta última noção, aliás, se atualiza sob o recente fenômeno do desemprego estrutural? Não estaria a desregulamentação da economia brasileira equalizando, mutatis mutandis, uma crescente precarização do trabalho na agricultura, tanto quanto na indústria e no comércio e serviços? Não estaria esse movimento de equalização entre indústria, comércio, prestação de serviços e agricultura, por estudiosos apontado e observado a partir dos anos 1980, antes já em desenvolvimento, específica e informalmente, sob o capital agroindustrial açucareiro de maneira particular?

Conforme Anexo, a condição de temporário do trabalho na atividade agroindustrial açucareira na safra 1994-1995 apresenta-se, em toda a região Nordeste, cerca de $50 \%$ superior àquele efetivamente permanente. A inversão de tal fenômeno pode ser aqui, grosso modo, acompanhada em sua trajetória histórica, pois, se aos canavieiros assalariados "sazonalmente" temporários se subtraiu, em grande medida, a condição de morador de outrora nas fazendas de cana-de-açúcar, tal qual demonstrado por (HEREDIA, 1988), acrescentaram-se os pequenos produtores agrícolas "temporariamente" canavieiros que, em torno de três décadas, combinam sua

\footnotetext{
${ }^{5}$ A noção marxista de exército industrial de reserva impõe-se a reflexões mediante o novo padrão flexível e volátil de acumulação do capital, na contemporaneidade, sob a primazia do capital financeiro. Ressaltemos, grosso modo, duas dimensões substantivas à formação e ao movimento do exército industrial de reserva no capitalismo, segundo Marx: 1) de uma parte, sua natureza estrutural, cuja existência é obstruir um aumento no preço da força de trabalho acima do seu valor num determinado setor produtivo e 2), de outra parte, sua natureza conjuntural, dada a possibilidade de sua absorção, isto é, de um excedente de força de trabalho - reserva de trabalhadores sob a forma de desempregados - em momentos de prosperidade econômica (MARX, 1975, pp. 438-9 - grifos nossos). A partir das duas últimas décadas, no entanto, em face da atual crise de valorização do capital, estudiosos no âmbito da sociologia do trabalho têm apontado a tendência de eliminação irreversível de postos de trabalho, portanto, de irreversibilidade de uma tendência regressiva do desemprego estrutural; a noção, assim, de exército industrial de reserva coloca-se historicamente à reflexão sociológica diante das novas formas heterogêneas e complexificadas de realização do trabalho em situações e processos característicos do atual desemprego estrutural, isto é, do desenvolvimento contraditório e multifacetado da (des)organização/ (des)estruturação do trabalho contemporâneo.
}

Latitude, Vol. 1, n'2, pp.119-134, 2007. 
situação de assalariado livre "temporariamente" no corte da cana-de-açúcar (no período de setembro-fevereiro em geral) com a sua condição de pequeno produtor de feijão, mandioca etc no sertão alagoano (no período de março-agosto).

\section{Da transição de morador ao trabalho assalariado livre e temporário na agroindústria canavieira}

Vários cientistas sociais observaram que o desenvolvimento contraditório e multifacetado da organização do trabalho, sob valorização e crises do capital em espaços urbanos e industrialmente desenvolvidos, não menos vem se impondo no campo através da modernização da agricultura (WANDERLEY, 1979; ANDRADE, 1998; SILVA, 1999; NOVAES e ALVES, 2007). Evidencia-se, na base territorial do presente estudo, o domínio do capital agroindustrial e de suas atividades produtivas nos fundamentos de parte preponderante do mundo do trabalho, bem como na organização político-administrativa do estado desde o Brasil-Colônia. Ao nosso ponto de partida, quais investigações sociológicas têm registrado, de maneira sistemática, a história do trabalho agroindustrial açucareiro em Alagoas, cuja imediaticidade mantém-se esparsa quando não pratica e dispersivamente invisível inclusive à academia? $^{6}$

Inicialmente, ressaltemos a publicação dos resultados de uma valiosa investigação realizada por (HEREDIA, 1988), no final dos anos 1970, sobre as relações sociais mantidas entre trabalhadores assalariados, pequenos produtores de subsistência, moradores e grandes proprietários de cultivo da cana-de-açúcar (senhores de engenho) ${ }^{7}$. Paulo Décio de Arruda Mello, por sua vez, investigou os impactos da reestruturação produtiva na ação sindical e o papel dos movimentos sociais rurais em Alagoas, a partir de 1985, destacando as transformações do setor sucroalcooleiro, o avanço das áreas plantadas e o impacto disso nas organizações dos trabalhadores ${ }^{8}$. Ao

\footnotetext{
${ }^{6}$ A despeito das recentes reivindicações de canavieiros divulgadas pela mídia local. A respeito, ver DUARTE, Flávia; GALVÃO. Trabalhadores de usina bloqueiam BR 101. TV Pajuçara/Alagoas 24 Horas, 22/11/2007, às 10 h.; Canavieiros invadem Usina Santa Clotilde. TV Pajuçara/Alagoas 24 Horas, 22/11/2007, às 10 h.; ___. Canavieiros impedem acesso à Santa Clotilde. TV Pajuçara/Alagoas 24 Horas, 22/11/2007, às 13 h.; FARIAS, Felipe. Usina responderá por danos morais - ação deverá ser ajuizada até o fim do mês por integrantes do Ministério do Trabalho. Gazeta de Alagoas, 29/02/08, Caderno Cidades, p. A15; O JORNAL. Grupos organizados desafiam o governo e invadem usinas - Invasões e paralisações vêm causando prejuízos ao setor canavieiro. O Jornal, 24/22/07, p. A3 (site: www.ojornal-al.com.br; e-mail: política@ojornal-al.com.br)

${ }^{7}$ Ver HEREDIA, 1988.

${ }^{8}$ Ver MELLO, 2002.
}

Latitude, Vol. 1, n², pp.119-134, 2007. 
lado das investigações anteriores, registremos o estudo de (ALBUQUERQUE,2003) sobre o esgotamento do sistema de moradia nas fazendas e as transformações ocorridas no universo canavieiro? .

O período expansivo e extensivo da atividade canavieira (1950-1975) à custa da incorporação de pequenas propriedades rurais atingiu, da mesma maneira, o sistema de moradia; este, que se combinava com o roçado de usufruto do trabalhador canavieiro e de sua família com o trabalho assalariado, atinge, não menos, aqueles trabalhadores assalariados e livres, temporariamente residentes em galpões de propriedade dos grandes fornecedores de cana. O sistema de morada, entrando em crise a partir dos anos 1950, em Alagoas, se aparentemente coincide com um período de expansão e modernização da agroindústria canavieira (1950-1975), na verdade delas resultam; sob esse processo de sua extinção, desenvolve-se a contínua proletarização do morador canavieiro ${ }^{10}$.

Manuel Correia de Andrade (1977), talentoso e arguto geógrafo pernambucano, analisou as mudanças ocorridas nas relações de trabalho no campo na década de 70, destacando ainda a figura do "empresário capitalista" enquanto personificação de um "capitalismo modernizado [que] chegava ao campo" sob uma de suas conseqüências mais agudas:

(...) O morador foi se transformando em assalariado e o processo de proletarização foi se intensificando gradativamente, à proporção que as safras aumentavam, que a usina incorporava mais terras às suas culturas e a população periférica das cidades e vilas ia se ampliando. Antigos moradores, desapropriados de seus sítios, se transferiram para a área urbana e passaram a prestar serviços como trabalhadores alugados, nos periodos em que as usinas e engenhos necessitavam de braços de forma mais intensa. Esse processo de proletarização se tornaria mais agudo na década de setenta, quando surgiram as grandes usinas que produziam mais de um milhão de sacos por safra. O impacto sobre o espaço produzido foi forte na transformação de centros urbanos característicos que eram habitados, sobretudo, por trabalhadores da cana (cf. Id., pp. 67-8).

\footnotetext{
${ }^{9}$ Ver ALBUQUERQUE, 2003.

${ }^{10}$ Cf. LIMA (1990). Dissertação de mestrado. Campinas: Instituto de Economia, Universidade de Campinas, 2001. É interessante observar o sistema de morada - "... base de sustentação do poder econômico e político dos senhores de engenho..." (HEREDIA, op. cit., p. 167 - grifos no original) enquanto uma das formas de resistência dos senhores de engenho ante o surgimento das usinas, dificultando e impedindo aos proprietários destas últimas o acesso à força de trabalho (LIMA, op. cit., p. 33).
}

Latitude, Vol. 1, n², pp.119-134, 2007. 
Sob a produção açucareira contemporânea, a constituição do trabalhador assalariado livre e "sazonalmente" temporário, em grande medida originário de uma base social fundada no sistema de morada característico dos grandes engenhos de cultivo da cana-de-açúcar, não apenas aprofunda a precarização das suas já precárias condições anteriores de vida e de trabalho em geral, bem como as dos demais membros sua família ${ }^{11}$; impulsiona, do mesmo modo, a intensificação da exploração absoluta da sua força de trabalho enquanto canavieiro, na medida em que o rendimento pela venda da força de trabalho torna-se condicionado à sua produtividade diária ${ }^{12}$. Tais alterações não se restringem à percepção, por parte do próprio canavieiro, de uma superexploração objetiva de sua força de trabalho; desenvolve-se, em sua subjetividade, um processo de deslocamento quanto à percepção de outros canavieiros: especificamente em relação ao trabalhador assalariado "sertanejo temporariamente canavieiro". A superexploração do seu trabalho e a deterioração das suas condições de vida pelo capital agroindustrial agudizam-se, na percepção objetiva e subjetiva do trabalhador assalariado "sazonalmente" (ou "permanentemente" temporário), com a presença dos canavieiros sertanejos, pois a estes é destinado o corte da cana em solos mais planos, mais favoráveis ao corte e à produtividade/tonelada/dia, propiciando-lhes em conseqüência uma maior remuneração.

Estabelece-se, por conseguinte, na subjetividade dos canavieiros, uma hierarquização no interior da sua própria categoria social em conformidade com as suas respectivas origens fisiográficas: entre os cortadores de cana do 'lugar' (residentes

${ }^{11}$ A título de esclarecimento, a noção de morador implicava automaticamente, segundo Heredia (1988), a existência de uma família do próprio trabalhador: "Nesse sistema, a existência da 'família' do morador ocupava um lugar central, lugar que era ressaltado no próprio ato de incorporação de trabalhadores enquanto moradores. ... Homens sozinhos não eram incorporados como moradores. ... 'Ter família' assumia tal importância que o morador que perdesse a mulher e não tivesse filhos que ficassem residindo com ele, deixando de constituir um grupo doméstico ["o conjunto de indivíduos que habitam uma mesma casa e possuem uma economia doméstica comum ..."] retornava à condição de solteiro, perdendo, em conseqüência, a casa e o acesso à parcela de cultivos" (id., ibid., pp. 130-1 - grifos no original).

12 Na Usina Santa Clotilde (Rio Largo/AL) estabelece-se o pagamento sob uma forma progressiva de produção:

- até 5 toneladas $\mathrm{R} \$ 3,00$; de 5 a 7 toneladas $\quad \mathrm{R} \$ 3,30$; acima de 7 toneladas $\mathrm{R} \$ 3,50$. A média do rendimento mensal dos canavieiros, na referida usina, situa-se em torno de $11 / 2 \mathrm{SM}$ a $2 \mathrm{SM}$; ao lado dessa média encontram-se casos de remuneração abaixo do próprio salário mínimo, numa jornada de trabalho que se inicia às 07:00 e se encerra às 17:00 h, com pausa para o almoço das 11:00 às 13:00 h; este último horário é raramente a rigor seguido, dado o sistema de remuneração segundo a forma progressiva de produção, cuja média, nesta mesma usina, situa-se entre 5 e 6 toneladas / dia (cf. entrevista de agenciador da referida usina concedida aos líderes do GP/CNPq, em 12/09/2007). O salário mínimo oficial até abril/2008 (R\$380,00) alterou-se para $R \$ 415,00$ a partir de maio/ 2008 .

Latitude, Vol. 1, n'2, pp.119-134, 2007. 
com a família no próprio município onde se localiza a usina na qual trabalham e / ou a ela circundantes e para a qual se deslocam diariamente) e os sertanejos, os do "nãolugar"13.

À constituição do trabalhador canavieiro moderno - assalariado e livre, "sazonal" ou "temporariamente "fichado" - opera-se analogamente uma mudança, por sua vez, na própria subjetividade patronal, isto é, na sua auto-identidade em termos do moderno capitalista agroindustrial. Dito de outro modo, os impactos da reestruturação produtiva e do conjunto de mudanças implicadas na produção do açúcar resultaram, por uma parte, na eliminação do morador, e no seu lugar formou-se uma categoria social combinada - constituída pelo canavieiro assalariado livre contratualmente assalariado, pelo canavieiro assalariado "sazonalmente" contratado e pelo pequeno produtor agrícola sertanejo "temporariamente" canavieiro assalariado na qual, contudo, subjetivamente se contrapõem, sobretudo entre os dois últimos, o canavieiro 'local' e o de 'fora' (o canavieiro migrante do sertão alagoano); de outra parte, percepção análoga se desenvolve na própria subjetividade do sujeito do capital agroindustrial. Ou seja, com o surgimento da usina - no seu bojo, ensejando o desaparecimento do engenho e, com ele, o senhor de engenho - surge o seu próprio sujeito - o usineiro -, no qual se centraliza, de forma combinada, o capital agrário e o capital industrial, numa palavra, o capital agroindustrial.

${ }^{13}$ À época do seu estudo, Heredia (1988) constata que a expressão sertanejo remetia a todos os trabalhadores não pertencentes ao 'lugar' - “O deslocamento diário ou semanal dos trabalhadores residentes na Área depende da distância entre os locais de trabalho e moradia. ... No caso de permanecerem durante a semana nas propriedades, os trabalhadores - residentes na própria Área ou em outras áreas - são alojados nos galpões juntamente com os trabalhadores sertanejos, denominação genérica dada àqueles que permanecem nas propriedades durante todo o período da safra, quando então retornam aos seus lugares de origem. Na realidade, a expressão sertanejos se relaciona à origem de parte desses trabalhadores, mas tornou-se um termo de uso mais geral para os proprietários uma vez que estes designam como sertanejos ao conjunto dos trabalhadores que, independentemente de sua origem, são alojados nos galpões" (id., p. 95-96); na atualidade, informações de entrevistados em geral e concedidas à autora e a um dos autores, indicam que a referência sertanejo denota uma correspondência mais circunscrita entre trabalho e sua origem de lugar fisiográfico, mormente adotada por geógrafos, ou seja, canavieiros sertanejos efetivamente oriundos da região do sertão alagoano. Nos termos de um engenheiro agrônomo da Usina

Santa Clotilde, havia conscientemente, por parte da empresa, uma clara preferência pelos cortadores de cana originários do sertão alagoano, pois, em ficando alojados nos galpões (localizados em domínios da Usina) ao longo de várias semanas consecutivas, ausentavam-se menos do trabalho, apresentavam menos atestados médicos a fim de justificarem faltas ao trabalho, ao contrário daqueles residentes com suas famílias no próprio município onde se localizava a Usina e/ ou a ela circundantes, e que diariamente se deslocavam ao local de trabalho (cf. entrevista concedida aos líderes do GP/CNPq, em 12/11/2007).

Latitude, Vol. 1, n², pp.119-134, 2007. 
A célere ampliação do monopólio territorial, político, econômico e social por parte do capital agroindustrial, apoiado pelos abundantes financiamento e proteção estatais, converte-se, todavia, moralmente, no seu contrário: a designação 'usineiro' passa a se tornar um apodo pejorativo e obsoleto, e o seu sujeito histórico luta, ainda nos dias atuais, para se auto-afirmar sob uma renovada identidade social: a de empresário, a de industrial; tais terminologias, afinal, o contemporizam com a modernização da agricultura e, portanto, elas próprias mais modernas para qualificar, reclassificando, o sujeito do capital industrial que se volta à industrialização da cana, da produção do açúcar e do álcool. Essas mudanças identitárias, como bem observou (ANDRADE, 1977), comportam profundos significados, pois a representação social do "empresário capitalista" sinaliza, finalmente, que o "capitalismo modernizado chegava ao campo".

O universo canavieiro alagoano desenvolve-se, entretanto, sob a mais característica modernização conservadora. De uma parte, temos os elementos da modernidade que avassaladoramente se impõem e, de outra, a sobrevivência, quando não o agravamento, de relações típicas de um contexto pré-industrial. A face avançada dessa modernização revela-se através de um dinâmico processo produtivo, marcado por uma crescente incorporação de novas técnicas e tecnologias, conforme as exigências do mercado global. No mesmo sentido, amplia-se o controle sobre o mundo laboral e aprimoram-se os mecanismos de exploração e os padrões de produtividade cada vez mais rigorosos do trabalho. O desdobramento perverso desse processo é o agravamento das condições de trabalho e de existência do canavieiro. Conforme ainda Andrade (1994):

\begin{abstract}
(...) Este processo está, naturalmente, ligado à dinâmica 'modernização', que, no caso em estudo, assim como na sociedade em geral, faz-se muito mais nas técnicas utilizadas do que nas relações sociais. O que se observa, muitas vezes, é que a modernização e o uso de uma tecnologia mais eficiente provocam mais a degradação da questão social do que a melhoria da qualidade de vida dos trabalhadores e da população (cf. Id., p. 151).
\end{abstract}

Finalizemos esse ponto, mutatis mutandis, recorrendo a uma longa citação de Marx (1977) a respeito das transformações operadas, já no século XIX, na agricultura inglesa sob a indústria moderna:

A indústria moderna atua na agricultura mais revolucionariamente que em qualquer outro setor, ao destruir o baluarte da velha sociedade, o camponês, substituindo-o pelo trabalhador assalariado. As necessidades de transformação social e a oposição de classes no campo são assim equiparadas às da cidade. Os métodos rotineiros e irracionais da agricultura são substituídos pela aplicação consciente,

Latitude, Vol. 1, n², pp.119-134, 2007. 
tecnológica da ciência. O modo de produção capitalista completa a ruptura dos laços primitivos que, no começo, uniam a agricultura e a manufatura. Mas, ao mesmo tempo, cria as condições materiais para uma síntese nova, superior, para a união da agricultura e da indústria, na base das estruturas que desenvolveram em mútua oposição. $\mathrm{Na}$ agricultura moderna, como na indústria urbana, o aumento da força produtiva e a maior mobilização do trabalho obtêm-se com a devastação e a ruína física da força de trabalho. E todo o progresso da agricultura capitalista significa progresso na arte de despojar não só o trabalhador mas também o solo; e todo o aumento da fertilidade da terra num tempo dado significa esgotamento mais rápido das fontes duradouras dessa fertilidade. ... A produção capitalista, portanto, só desenvolve a técnica e a combinação do processo social de produção, exaurindo as fontes originais de toda a riqueza: a terra e o trabalhador (Id., ibid., pp. 578-579).

\section{Canavieiros: trabalhadores assalariados livres 'sazonalmente' temporários e "temporariamente" assalariados - uma nova categorial social e/ou desemprego estrutural?}

Uma discussão sobre a categorização social dos canavieiros constituída de trabalhadores assalariados livres contratados por tempo indeterminado, de assalariados livres sob contratados de safra (os "sazonais" ou "permanentemente" temporários) e de pequenos produtores agrícolas "temporariamente" canavieiros assalariados também sob contratos de safra nos remete à sua abordagem sob ângulos sociológicos. Tal debate não será, todavia, aqui retomado em profundidade, senão apenas brevemente indicado numa parcela ínfima da literatura a respeito.

Poder-se-ia tomar como pressuposto que os canavieiros constituem, segundo a acepção de (GRAMSCI, 1968), uma categoria social na divisão social do trabalho pelo peso da atividade (mais muscular-nervosa) e pela função social/profissional especializada que desempenham na totalidade das relações sociais (portanto, nas relações das classes sociais do ponto de vista histórico-concreto). Constituem-se, enfatiza (FERNANDES, 1977) em conformidade ao raciocínio de Gramsci, parte de uma determinada classe social precisamente por realizarem uma função social $e$ profissional especializada e não por uma abstrata e geral origem social de classe, embora "a classe constitui, de fato, o fundamento do conceito de categoria" (GRAMSCI, 1977, p. 137).

Quais funções sociais, entretanto, realiza a categoria dos canavieiros no conjunto complexo das relações das classes sociais? Antes de tudo, em sendo o açúcar produzido sob uma organização técnica do processo de trabalho em cuja unidade territorial e econômico-social unificou-se o capital industrial e o capital agrário, o próprio capital agroindustrial reuniu, sob seus domínios, não apenas o trabalho

Latitude, Vol. 1, n'2, pp.119-134, 2007. 
intelectual de um engenheiro agrônomo e/ou de um bioquímico, entre outros trabalhos produtivos na atividade açucareira, mas igualmente a força de trabalho empregada quer seja no ramo efetivamente industrial, quer seja no ramo propriamente agrícola ${ }^{14}$. É, assim, nos laboratórios, na indústria e na agricultura que suas respectivas categorias sociais (engenheiros agrônomos, bioquímicos, operários e canavieiros etc) realizam e operam, sob a divisão do trabalho simples "elos" do trabalhador coletivo, nos termos de (MARX, 1978, p. 72) a socialização do trabalho total. A divisão social do trabalho conecta unitariamente, desse modo, as diferentes categorias sociais de trabalhadores que concretamente vão se formando e historicamente dão existência efetiva à classe que vende a força de trabalho, integrando-as sob a categoria de trabalhador coletivo (uma crescente capacidade de trabalho socialmente combinada, segundo ainda Marx sobre a definição do trabalho produtivo (MARX, p. 71); esta última, sobretudo a partir dos anos 1980, se diversificou, se heterogeneizou e se complexificou, nos termos de (ANTUNES, 1998) dissimulando, não raras vezes, o desemprego estrutural. Pode-se dizer, numa frase, que o Estado institucionalizou, no país, não apenas a flexibilização do contrato de trabalho, mas igualmente a própria desestruturação do mercado de trabalho, bem como o aumento e a diferenciação do desemprego estrutural (cíclico, sazonal, oculto, instável, transitório, de elevada rotatividade, em suma, o trabalho "temporariamente" volante e/ou "permanentemente" temporário) ${ }^{15}$.

De uma parte, e a fim de abreviar as considerações acerca do conceito aqui objeto de discussão, se pode caracterizar, grosso modo, a complexidade das relações sociais nas quais se inserem, sob um trabalho socialmente combinado, o assalariado formalmente livre e contratualmente mais estável na organização do trabalho agroindustrial açucareira e aqueles "permanentemente" temporários e "temporariamente" assalariados, especificamente em parcela de sua atividade agrícola, como contemporizar tais formas de socialização e (des)estruturação do trabalho sob o recente fenômeno de desemprego estrutural? Ou ter-se-ia, de fato, formado não somente o proletariado moderno na agricultura, mas simultaneamente um excedente de força de trabalho o exército de reserva, por Marx apresentado em "A chamada acumulação primitiva" (MARX, 1975, pp. 828-882)? Em outros termos, conservar-se-ia

\footnotetext{
${ }^{14}$ Há, aqui, que se ressaltar uma importante observação de Cícero Péricles de Oliveira Carvalho: “o combate biológico às pragas é realizado por todas as empresas, sendo que algumas delas mantêm laboratórios em suas instalações ou terceirizaram estas atividades. A incorporação de novas variedades é feita pela importação de canas paulistas da Copersucar, por cuja utilização se pagam royalties e, por variedades desenvolvidas pelo Programa de Melhoramento Genético da Cana-deAçúcar, da RIDESA, da qual participa a UFAL " (op. cit.,, p. 48).

${ }^{15}$ A respeito da relação intrínseca entre a desestruturação e desregulação do trabalho no Brasil, ver, por exemplo, CARDOSO Jr., José Celso (2001).
}

Latitude, Vol. 1, n'2, pp.119-134, 2007. 
sua imediata correspondência com a indissociabilidade sazonal da produção agrícola ou configurar-se-ia, mas contemporaneamente, uma forma explícita de flexibilização, portanto, de desregulação das relações de trabalho na agricultura, tal qual se desenvolve, desde os anos 1980, na indústria, no comércio e na prestação de serviços nos grandes centros urbanos? Ou nele embute-se um efetivo desemprego estrutural, na agroindústria açucareira antecipado antes mesmo da década de 1980 ?

Com efeito, novos elementos têm se realçado nas análises e interpretações das diferentes formas de socialização e (des)estruturação do trabalho no Brasil e, à sua luz, é-nos permitido recuperar e aproximar tais reflexões sobre o trabalho assalariado "permanentemente" temporário (ou "sazonal") e o "temporariamente" assalariado do pequeno produtor agrícola, tal como é o caso dos canavieiros, diga-se, não apenas em Alagoas.

Se a desregulação do mercado de trabalho equaliza atualmente fenômenos, seja na indústria, seja na agricultura - embora sobressaíssem, em seu início, na grande indústria, no comércio e na prestação de serviços dos grandes centros urbanoindustriais -, tinha-se por objetivo, de uma parte, atender a parcelas do capital atingidas pela crise econômica mundial e brasileira, mas não menos, por outra parte, aniquilar a força organizativa da classe trabalhadora naqueles setores com larga tradição de resistência sindical e política; setores estes nos quais a organização técnica da produção e da socialização do trabalho tornaram-se objeto da reestruturação produtiva enquanto resposta liberalizante à rigidez do fordismo e do taylorismo.

Ao sugerirmos aqui a equalização, em termos de flexibilização e (des)estruturação do mercado de trabalho na indústria, no comércio e prestação de serviços urbanos tanto quanto na agricultura, partimos do suposto que a desregulamentação da economia brasileira atinge indistintamente os trabalhadores urbanos (indústria, comércio e prestação de serviços) tanto quanto os trabalhadores no campo. A socialização do trabalho no corte da cana-de-açúcar assume, portanto, formas multifacetadas - canavieiro assalariado "sazonalmente" temporário, "temporariamente" canavieiro do pequeno produtor agrícola sertanejo, outros contratualmente indeterminados e "polivalentes" (à medida que, na entressafra do corte da cana, são deslocados a outras tarefas não apenas agrícolas [plantio, limpa de terreno] mas também características do espaço fabril [auxiliares na manutenção e reparo, por exemplo, de equipamentos industriais que exigem baixa qualificação etc]) ; a intermitência preponderante nessas formas diversificadas de socialização do trabalho perde, assim, um atributo "natural" vinculado à sazonalidade da produção agrícola. Converte-se inclusive, tal qual na indústria, no comércio e na prestação serviços urbanos, em desemprego estrutural dissimulado ao se revelar sob um processo contraditório, heterogêneo e complexificado de desenvolvimento e de organização do trabalho em geral.

Latitude, Vol. 1, n'2, pp.119-134, 2007. 
$\mathrm{Na}$ atual atividade agroindustrial açucareira, em outros termos, pode-se indicar a formação de uma categoria social constituída não só de canavieiros assalariados livres contratados por tempo indeterminado e polivalentes", senão também de canavieiros assalariados livres parcialmente contratados ("sazonal" ou "permanentemente" temporários), bem como de pequenos produtores agrícolas sertanejos "temporariamente" canavieiros assalariados. Categoria profissionalmente especializada, em suma, cujas funções sociais caracterizam-se, na contemporaneidade, por ambivalências resultantes de um processo sob tripla dimensão - "precarização do precário" / desqualificação do trabalho/desemprego estrutural que dissimula, com freqüência, causalidades de natureza social sob a aparência natural da sazonalidade da produção agrícola ${ }^{16}$

\section{Considerações finais}

O propósito de concentrar a pesquisa empírica no município de Coruripe, situado na zona da mata alagoana, deve-se à localização, nesse município, das usinas que já detiveram a maior produção de açúcar e de álcool no estado no período de 1975 a 1985 (HEREDIA, 1988, p. 73; LIMA, 2001, p. 69). Em conseqüência, o trabalho dos canavieiros na parte agrícola das usinas lá localizadas nos servirá como um caso de referência para a análise de processos de organização do trabalho em fases distintas: ora sob um padrão de acumulação do capital agroindustrial açucareiro fortemente estimulado, amparado e protegido pela intervenção estatal, portanto ora via subsídios,

${ }^{16}$ Retomemos esclarecimentos adicionalmente com complementos: nos períodos de entressafra da cana-de-açúcar, há particularidades que diferenciam as condições de vida e de trabalho dos canavieiros - os residentes nas áreas urbanas dos municípios e/ou adjacentes, onde se situam inúmeras usinas e destilarias, cujo deslocamento ao local de trabalho é diário, não logram, em geral, alocar-se efetivamente em outros postos de trabalho (a fim de sobreviverem, não raro recorrem ao auxílio de familiares [de uma genitora que recebe, por exemplo, aposentadoria] ou, então, executam raros "bicos" pelos quais recebem uma remuneração deveras aquém daquela de um dia de trabalho nos canaviais). Circunstância inversa torna-se vivenciada pelos canavieiros migrantes sertanejos: diferentemente dos canavieiros "permanentemente" temporários, ocupamse, no mesmo período da entressafra da cana-de-açúcar (março-agosto), de sua pequena produção de feijão, mandioca, etc., cujo fim da colheita destes gêneros coincide com o início da safra da cana-de-açúcar. A estes últimos, tornarem-se canavieiros assalariados "temporariamente" migrantes alojados nos barracões das usinas, foi a forma encontrada à sua capacidade de sobrevivência, bem como à de sua família, no período de entressafra da sua pequena produção agrícola; não fosse esse processo contínuo de socialização do trabalho (ora familiar, ora sob forma assalariada) em condições objetivas nas quais ocorrem - entressafra da grande produção/safra da pequena produção -, a experiência do desemprego estrutural serlhes-ia tão similar quanto à daqueles canavieiros "permanentemente" temporários e tampouco seriam menos submetidos ao mesmo processo de crescente "precarização do precário" / desqualificação do trabalho/ desemprego estrutural.

Latitude, Vol. 1, n'2, pp.119-134, 2007. 
ora pela retração daqueles abundantes financiamentos; ademais dos seus efeitos no movimento do capital agroindustrial e na socialização do trabalho, é uma das áreas canavieiras à qual são dirigidos, com primazia, os trabalhadores assalariados "temporariamente" canavieiros migrantes sertanejos, complementarmente à sua condição de pequenos produtores agrícolas no sertão alagoano.

De todo o precedente, registremos que as reflexões, aqui ainda embrionárias, inserem-se numa preocupação mais abrangente de estudiosos que tomam as condições de vida e de trabalho dos canavieiros contemporâneos como objeto de investigação. Nesse sentido, duas publicações sobre os processos de trabalho dos cortadores de cana, em São Paulo e alhures, tornaram-se, desde 1990, referências especialmente indispensáveis às novas investigações temáticas ${ }^{17}$. Embora tomemos por base territorial o estado de Alagoas, no qual regionalmente se expressam movimentos específicos da socialização do trabalho, cremos entretanto que tais movimentos preservam, em seu cerne, uma unidade em sua diversidade; contribuir, de uma ou outra maneira, para a história do trabalho no setor canavieiro sob a sua dupla dimensão, objetiva e subjetiva, torna-se fundamental num período de suposta inação dos seus sujeitos. Sob tais aspectos, entre outros, apóia-se, em suma, este objetivo do Grupo de Pesquisa do CNPq: Trabalho e capitalismo contemporâneo: apreender as formas diversificadas, combinadas e complexificadas que assume a socialização do trabalho na agroindústria açucareira em Alagoas.

\section{Bibliografia}

ANDRADE, Manuel Correia de. Usinas e destilarias das Alagoas: uma contribuição ao estudo da produção do espaço. Maceió: EDUFAL, 1997.

. Modernização e Pobreza: a expansão da agroindústria canavieira e seu impacto ecológico e social. São Paulo: Editora da Universidade Estadual Paulista, 1994.

${ }^{17}$ Ver SILVA, Maria Aparecida de Moraes (1999) e NOVAES, José Roberto e ALVES, Francisco (orgs.) (2007).

Latitude, Vol. 1, n'2, pp.119-134, 2007. 
ALBUQUERQUE, Cícero Ferreira de. Em nome da liberdade: o esgotamento do sistema de moradia e o aumento do poder de barganha de voto em Atalaia no período de 1988 a 2000. Recife. Sociologia. [Dissertação (mestrado). Universidade Federal de Pernambuco, 2003

ANTUNES, Ricardo. Adeus ao trabalho?. $5^{\text {a }}$. ed. São Paulo: Cortez; Campinas, São Paulo: Editora da Universidade Estadual de Campinas, 1998.

CARDOSO Jr., José Celso. Crise e desregulação do trabalho no Brasil. In: Revista de Sociologia da USP- Tempo Social, São Paulo, Vol. 13(2), p. 31-59, novembro, 2001.

CARVALHO, Cícero Péricles de Oliveira. Análise da reestruturação produtiva da agroindústria sucroalcooleira alagoana. Maceió: EDUFAL, 2000.

PINDORAMA: a cooperativa como alternativa ou as razões que fizeram possível a inserção competitiva de ação de pequenos produtores numa região dominada pelo latifúndio, monocultura e trabalho servil. Maceió: EDUFAL, 2005.

DUARTE, Flávia; GALVÃO, Cláudia. Trabalhadores de usina bloqueiam BR 101. TV Pajuçara/Alagoas 24 Horas, 22/11/2007, às 10 h.

. Canavieiros invadem Usina Santa Clotilde. TV Pajuçara/Alagoas 24 Horas, 22 nov.2007, às $10 \mathrm{~h}$.

.Canavieiros impedem acesso à Santa Clotilde. TV Pajuçara/Alagoas 24 Horas, 22 nov. 2007 , às $13 \mathrm{~h}$. .

FARIAS, Felipe. Usina responderá por danos morais - ação deverá ser ajuizada até o fim do mês por integrantes do Ministério do Trabalho. Gazeta de Alagoas, Maceió, 29 fev.2008. Caderno Cidades, p. A15.

FERNANDES, Heloisa Rodrigues. O militar como categoria social. São Paulo. Sociologia. [Tese (doutorado). USP, 1977.

GRAMSCI, Antonio. Os intelectuais e a organização da cultura. Rio de Janeiro: Civilização Brasileira, 1968.

HEREDIA, Beatriz Alasia de. Formas de dominação e espaço social - A modernização da agroindústria canavieira em Alagoas. São Paulo: Marco Zero; [Brasília, DF]: $\mathrm{MCT} / \mathrm{CNPq}, 1988$.

LIMA, Araken Alves de. A agroindústria canavieira alagoana - Da criação do IAA à desregulamentação na década de 1990. Campinas. [Dissertação (mestrado). Instituto de Economia da Unicamp, 2001

MARX, Karl. O capital, $3^{\text {a }}$ ed. Rio de Janeiro: Civilização Brasileira, 1(1), 1975.

Latitude, Vol. 1, n'2, pp.119-134, 2007. 
O capital - Livro I - Capítulo VI (inédito). São Paulo: Livraria Editora Ciências Humanas, 1978.

MELLO, Paulo Décio de Arruda. Cana-de-açúcar e reestruturação produtiva: ação sindical e os movimentos sociais rurais em Alagoas a partir de 1985. Recife. [Tese (doutorado)]. Programa de Pós-Graduação em Sociologia da Universidade Federal de Pernambuco, 2002.

NOVAES, José Roberto e ALVES, Francisco (Orgs.). Migrantes: trabalho e trabalhadores no complexo agroindustrial canavieiro (os heróis do agronegócio brasileiro). São Carlos: EDUFSCAR, 2007.

O JORNAL. Grupos organizados desafiam o governo e invadem usinas - Invasões e paralisações vêm causando prejuízos ao setor canavieiro. O Jornal, p. A3. Disponibilibidade: $<$ htpp// www.ojornal-al.com.br> Acesso 24 nov. 2007.

OLIVEIRA, Francisco. Entre Marx, Dickens e Zola (Prefácio). In: NOVAES, José Roberto e ALVES, Francisco. Op. cit., pp. 7-9.

. O pós-moderno. In: Folha de S. Paulo, 27 mai. 2007, Caderno Mais!, p. A3.

SILVA, Maria Aparecida de Moraes. Errantes do fim do século. São Paulo: Fundação da Editora da UNESP, 1999.

WANDERLEY, Maria de Narareth B. Capital e Propriedade Fundiária na Agricultura Brasileira. Rio de Janeiro: Paz e Terra, 1979.

Latitude, Vol. 1, n'2, pp.119-134, 2007. 